\title{
Contribution of NR2B Subunits to Synaptic Transmission in Amygdaloid Interneurons
}

\author{
Csaba Szinyei, Oliver Stork, and Hans-Christian Pape \\ Institute of Physiology, Medical School, Otto-von-Guericke University, 39120 Magdeburg, Germany
}

Synaptic responses of interneurons in the rat lateral amygdala (LA) to electrical microstimulation of putative cortical and thalamic afferents were studied in slice preparations in situ. The EPSPs at both thalamic and cortical inputs were composed of two major components that were sensitive to 6,7-dinitroxaline-2,3-dione and DL-2-amino-5-phosphonovaleric acid (APV), indicating mediation through AMPA and NMDA receptors. NMDA receptor activation contributed to basal synaptic transmission, as evidenced through a reduction of EPSP amplitudes and integrals by APV. NMDA receptor-mediated postsynaptic currents showed magnesium-regulated voltage dependence, and current-voltage relationships displayed a region of negative slope conductance negative to resting potential. Deactivation of NMDA receptor-mediated currents followed a two exponential time course, with both components being significantly reduced by ifenprodil $(10 \mu \mathrm{M})$, an antagonist of the NR2B subunit of NMDA receptors. Significant differences were not observed between NMDA currents or ifenprodil effects at thalamic and cortical inputs. Furthermore, recordings from a sample of projection neurons in the LA provided additional evidence for the existence of ifenprodil-sensitive components of thalamically and cortically evoked NMDA receptor-mediated responses. Immunohistochemical double-labeling and combined in situ hybridization/immunohistochemistry demonstrated that GABA-immunoreactive as well as GABA-negative cells express the NR2B subunit. Overall, these results show that GABAergic interneurons in the LA express functional NMDA receptors, which participate in basal synaptic transmission at both thalamic and cortical inputs. The finding that NR2B subunits are critically involved in NMDA receptor-mediated signaling at the two major input pathways to interneurons and projection cells in the LA is particularly interesting in the light of previous observations that NR2B antagonists interfere with plastic changes in the LA related to associative fear conditioning.

Key words: lateral amygdala; projection neuron; interneuron; inhibition; NMDA receptors; NR2B subunit

\section{Introduction}

The amygdaloid complex is known to be important for the regulation of emotional behavior and learning (LeDoux, 2000; Davis, 2002 ) and to be critically involved in neurological disorders, such as temporal lobe epilepsy (Gloor, 1992), post-traumatic stress syndrome, and depression (Levine et al., 2001). As the main sensory input station of the amygdala, the lateral amygdaloid nucleus (LA) receives sensory information from cortical and subcortical fields. Cortical afferents reach the LA laterally from the external capsule, and the subcortical thalamic afferents arrive medially from the internal capsule (LeDoux et al., 1991; Turner and Herkenham, 1991; Romanski and LeDoux, 1993; McDonald, 1998). These two main sensory inputs converge on populations of principal cells (Li et al., 1996) and interneurons (Lang and Paré, 1998, Szinyei et al., 2000), which in the LA can be classified based on electrophysiological, neurochemical, and morphological properties (Rainnie et al., 1991; Lang and Paré, 1998; Mahanty and Sah, 1998). In vivo data demonstrated a powerful control through GABAergic inhibition over the activity of projecting principal cells (Lang and Paré, 1997, 1998), which renders a special role to the GABAergic interneurons in the control of excita-

Received 0ct. 10, 2002; revised Dec. 16, 2002; accepted Jan. 7, 2003.

This work was supported by the Deutsche Forschungsgemeinschaft (SFB 426, TP B3) and by the Kultusministerium des Landes Sachsen-Anhalt. We thank R. Ziegler, A. Reupsch, and M. Schmidt for expert technical assistance.

Correspondence should be addressed to Hans-Christian Pape, Institute for Physiology, Medical School, Otto-vonGuericke University, Leipzigerstrasse 44, 39120 Magdeburg, Germany. E-mail:

hans-christian.pape@medizin.uni-magdeburg.de.

Copyright $\odot 2003$ Society for Neuroscience $\quad 0270-6474 / 03 / 232549-08 \$ 15.00 / 0$ tion in this region. Indeed, GABAergic interneurons are thought to play a crucial role in information processing in the amygdala (Lang and Paré, 1997; Mahanty and Sah, 1999) and to participate to the regulation of epileptiform activity (Callahan et al., 1991; Gloor, 1992; Washburn and Moises, 1992a,b) as well as fear and anxiety (Pesold and Treit, 1995; Sanders, 1995) through this region.

With respect to fast excitation, AMPA and NMDA receptormediated responses were shown to coexist at both pathways to LA projection neurons (Mahanty and Sah, 1999; Weisskopf and LeDoux, 1999). Converging fast excitatory postsynaptic responses from cortical and thalamic inputs were also found in interneurons of the LA (Szinyei et al., 2000). The cortical glutamatergic inputs onto interneurons in the lateral and basolateral nucleus of the amygdala were reported to impinge on AMPA receptors, the $\mathrm{Ca}^{2+}$ permeability of which promoted a particular form of longterm synaptic plasticity, whereas NMDA receptor-mediated signals were reported to be very small or negligible in these types of neurons (Mahanty and Sah, 1998). On the contrary, experiments on LA interneurons using pressure application of NMDA showed that the respective receptors are functional in interneurons, although the mediating synaptic inputs were not identified (Danober et al., 2000).

The present study was undertaken to investigate in detail the possible role of NMDA receptor activation for synaptic signaling in LA interneurons. The following findings were of particular interest for the design of the study: differences in voltagedependent properties of NMDA receptor-mediated synaptic re- 
sponses associated with thalamic and cortical inputs to LA projection neurons (Weisskopf and LeDoux, 1999; but see Mahanty and Sah, 1999) and the critical contribution of the NR2B subunits of NMDA receptors to plastic changes in LA projection neurons associated with fear conditioning in the amygdala (Rodrigues et al., 2001; Bauer et al., 2002). In view of these findings, particular emphasis was put on a comparison between NMDA receptor activation and properties associated with thalamic and cortical input fibers and the contribution of NR2B subunits to these responses in interneurons.

\section{Materials and Methods}

Whole-cell patch-clamp recordings. Slices containing the amygdala from Long-Evans rats of either sex (postnatal days 21-28) were prepared, and recordings were performed as described previously (Szinyei et al., 2000). Briefly, rats were anesthetized with halothane and killed by decapitation. After the preparation and equilibration of $300-\mu \mathrm{m}$-thick coronal slices in a sucrose-containing solution [composed of the following (in $\mathrm{mM}$ ): 20 piperazine- $N, N^{\prime}$-bis-2-ethanesulfonate, $2.4 \mathrm{KCl}, 0.5 \mathrm{CaCl}_{2}, 10 \mathrm{MgSO}_{4}$, 10 glucose, and 195 sucrose, with $\mathrm{pH}$ adjusted to 7.25 with $1 \mathrm{M} \mathrm{NaOH}$ and saturated with $\mathrm{O}_{2}$ ], recordings were obtained under visual guidance (Axioskop FS, Achroplan 40/w; Zeiss, Oberkochen, Germany) using infrared videomicroscopy (C-2400 black-and-white camera, Hamamatsu, Hersching, Germany). Experiments were done at $30^{\circ} \mathrm{C}$ in a submerged-type chamber. The extracellular solution contained the following concentration of chemicals (in mM): $125 \mathrm{NaCl}, 2.5 \mathrm{KCl}, 1.25 \mathrm{NaH}_{2} \mathrm{PO}_{4}, 22$ $\mathrm{NaHCO}_{3}, 2 \mathrm{MgSO}_{4}, 2 \mathrm{CaCl}_{2}$, and 20 glucose, with $\mathrm{pH}$ adjusted to 7.3-7.4 through bubbling with $95 \% \mathrm{O}_{2}$ and $5 \% \mathrm{CO}_{2}$. Electrophysiological recordings were performed using the patch-clamp technique in whole-cell mode. Patch pipettes were pulled from borosilicate glass (2.5-3.5 M $\Omega$, GC150T-10; Clark Electromedical Instruments, Pangbourne, UK), and experiments were performed with a potassium-based internal solution containing the following (in $\mathrm{mm}$ ): $95 \mathrm{~K}$-gluconate, $20 \mathrm{~K}_{3}$-citrate, 10 $\mathrm{NaCl}, 10$ HEPES, 0.5 EGTA, $1 \mathrm{MgCl}_{2}, 3 \mathrm{MgATP}$, and $0.5 \mathrm{NaGTP}$, with $\mathrm{pH}$ adjusted to 7.25 with $1 \mathrm{~m} \mathrm{KOH}$. To stimulate afferent fibers, bipolar tungsten stimulation electrodes were placed in the external capsule and in the internal capsule dorsal to the central nucleus of the amygdala similarly as described previously (Mahanty and Sah, 1999; Weisskopf and LeDoux, 1999; Heinbockel and Pape, 2000; Szinyei et al., 2000). Stimuli (100 $\mu \mathrm{sec}$ pulse duration, $0.1-5 \mathrm{~mA}$ ) were used to evoke synaptic responses recorded with an Axopatch 200B amplifier (Axon Instruments, Foster City, CA). Access and input resistance were continuously monitored. Access resistance was in the range of $8-16 \mathrm{M} \Omega$. Data were omitted if access resistance or input resistance changed by $>20 \%$ during the course of the experiment. Liquid junction potentials in all voltage-clamp experiments were corrected (Neher, 1992). For stimulation, membrane potential control, and data acquisition, pClamp 8.0 software (Axon Instruments) was used. Data were low-pass-filtered at $2 \mathrm{kHz}$ with the Bessel filter of the amplifier and digitized at $10 \mathrm{kHz}$ by a Digidata 1200 (Axon Instruments). Interneurons were identified according to their electrophysiological properties (Washburn and Moises, 1992a; Rainnie et al., 1993; Mahanty and Sah, 1998; Szinyei et al., 2000). After obtaining the cells in voltage-clamp mode, current-clamp mode was chosen to characterize intrinsic membrane and firing properties of the interneurons. Cells that showed high-frequency firing of fast action potentials after the injection of +0.1 to $+0.4 \mathrm{nA}$ current with distinct fast afterhyperpolarization after each spike and no apparent spike frequency adaptation were considered to be interneurons. Classification was confirmed through morphological features (lack of dendritic spines) after histological processing.

Drug application. The following drugs were purchased (if not otherwise stated) from Sigma (St. Louis, MO) and applied during the experiments: DL-2-amino-5-phosphonovaleric acid (APV), ifenprodil, and (2S)-3-\{[(15)-1-(3,4-dichlorophenyl)ethyl]amino-2-hydroxypropyl)(phenylmethyl)phosphinic acid (CGP55845; obtained from Tocris Cookson, Bristol, UK) were diluted directly in the external solution. Picrotoxin was predissolved at $100 \mathrm{~mm}$ in ethanol $(95 \%$ $\mathrm{v} / \mathrm{v}) ; 6,7$-dinitroxaline-2,3-dione (DNQX) was prepared at $20 \mathrm{~mm}$ in $100 \%$ DMSO.
Analysis of synaptic responses and drug effects. After baseline stabilization, EPSPs were recorded on alternating stimulation at $0.05 \mathrm{~Hz}$ of thalamic and cortical input fibers. Amplitudes were averaged from 10 consecutive EPSPs, separately for each pathway, and these were considered controls. The effects of an applied drug were considered maximal if a stable new baseline was obtained. Amplitudes were averaged from 10 consecutive EPSPs and normalized with respect to the control values, separately for each input pathway. For experiments with repetitive stimulation (10 pulses at $2 \mathrm{~Hz}$ ), stimuli were delivered twice at $20 \mathrm{sec}$ intervals. The APV-sensitive response component was obtained as the graphic difference of responses under control conditions and the maximal action of APV. Integrals were calculated as the summed amplitudes of EPSPs (sampling rate at $10 \mathrm{kHz}$ ) under the different experimental conditions. To obtain current-voltage $(I-V)$ relationships of EPSCs under voltageclamp conditions, interneurons were initially stepped to $+50 \mathrm{mV}$, the resulting outward current was allowed to settle to a steady-state value (average holding current at $+50 \mathrm{mV}$ was $+1.03 \pm 0.1 \mathrm{nA} ; n=11$ ), and after recording of evoked EPSCs at that potential, less-positive holding potentials were approached in a stepwise manner. This protocol allowed fair voltage control of EPSCs, as indicated by smooth $I-V$ curves and similar values of reversal potentials of EPSCs recorded in different cells under different experimental conditions. For the construction of $I-V$ relationships, EPSCs were normalized with respect to the absolute value of the EPSC amplitude at $-50 \mathrm{mV}$ in $0.1 \mathrm{~mm} \mathrm{Mg}^{2+}$ (giving maximal synaptic inward current).

When standard double-exponential fits were applied to the decay phase of averages of EPSCs, the value of the correlation coefficient was always $>0.96$. The following equation was used: $y=A_{0}+A_{1} \times \exp (-t)$ $\left.\tau_{1}\right)+A_{2} \times \exp \left(-t / \tau_{2}\right)$, with $A_{n}$ and $\tau_{n}$ representing amplitude and time constant, respectively.

Statistical analysis. For statistical analysis, the two-tailed paired $t$ test was applied. Populations were regarded as significantly different if $p$ was $<0.05$. Data are expressed as means \pm SEM.

Histological procedures. Biocytin labeling and light-microscopic morphological analysis were performed as described previously (Szinyei et al., 2000). Briefly, 1\% biocytin was added to the intracellular solution. After recording, slices were immersed in 4\% paraformaldehyde in PBS. After cryoprotection with a $30 \%$ sucrose solution in PBS, slices were resectioned at $100 \mu \mathrm{m}$ using a freeze microtome (Leica, Benzheim, Germany). Sections were treated with avidin-biotin complex horseradish peroxidase (PK 4000, 1:100; Vector Laboratories, Burlingame, CA) and then treated with $\left(\mathrm{NH}_{4}\right)_{2} \mathrm{Ni}\left(\mathrm{SO}_{4}\right)_{2}$. Finally, sections were dehydrated and coverslipped.

Immunohistochemistry and in situhybridization. The expression of NR2B subunits on GABA-immunoreactive cells of the LA was demonstrated with double-immunohistochemistry and combined in situ hybridization/immunohistochemistry double-labeling. For both methods, slices of the LA and adjacent areas after recording were fixed in $4 \%$ paraformaldehyde and $0.05 \%$ glutaraldehyde overnight. Cryoprotection was done with $30 \%$ sucrose, and coronal sections of 20 and $40 \mu \mathrm{m}$ thickness were cut on a freeze microtome.

Double-immunohistochemistry was performed on $40-\mu \mathrm{m}$-thick sections with a free-floating method. After washing in PBS buffer and blocking of unspecific binding with a solution of $10 \%$ goat normal serum, $2 \%$ BSA, and $0.3 \%$ Triton X-100 in PBS, sections were incubated overnight with a polyclonal anti-NR2B antibody (Chemicon, Temecula, CA) diluted 1:500 in the blocking solution. After washing in PBS, primary antibodies were detected with biotinylated secondary antibodies and $\mathrm{Cy} 3-$ streptavidin complex according to the manufacturer's protocol (Sigma). Subsequently, GABA was detected with a monoclonal antibody (Sigma) diluted 1:400 in blocking solution. After overnight incubation and washing in PBS, signals were visualized with Alexa goat anti-mouse fluorescent antibody (obtained from Molecular Probes, Eugene, OR) diluted 1:300 in $0.2 \%$ Triton X-100 in PBS. Stained sections were washed, embedded with medium Immu-Mount (Shandon-Lipshaw, Pittsburgh, PA), and coverslipped. Negative controls were prepared in parallel experiments with the omission of anti-NR2B or anti-GABA primary antibodies.

For in situ hybridization/immunohistochemistry double-labeling, 20- 
$\mu \mathrm{m}$-thick sections were cut and thaw-mounted onto silane-coated slide glasses. After overnight permeabilization with $0.3 \%$ Triton X-100 and subsequent quenching of endogenous peroxidase activity with $0.3 \%$ $\mathrm{H}_{2} \mathrm{O}_{2}$, GABA-immunoreactive cells were detected by immunohistochemistry. Unspecific binding was blocked with $10 \%$ normal serum and $2 \%$ BSA in PBS, and GABA was detected with a polyclonal antibody from Sigma at a dilution of 1:1000 in blocking solution. Labeling was detected using the $\mathrm{ABC}$ method (Vectastain) and 3-amino-9-ethylcarbazole chromogen (Sigma), according to the manufacturers' protocols. After development of the GABA staining, sections were immediately processed for in situ hybridization (Stork et al., 2001). In brief, sections were acetylated, prehybridized for $2 \mathrm{hr}$ at $37^{\circ} \mathrm{C}$, and hybridized overnight at $42^{\circ} \mathrm{C}$ with a digoxigenin-labeled cRNA probe generated from a $299 \mathrm{bp}$ fragment of the NR2B coding region (3338-3636 bp according to sequence $\mathrm{NM}$ 008171). Stringency washing was done at $50^{\circ} \mathrm{C}$ with $0.1 \%$ SSC and $50 \%$ formamide as the final concentration, and labeled cells were detected with alkaline-phosphatase-coupled antidigoxigenin antibodies using nitroblue tetrazolium chloride and 5-bromo-4-chloro-3-indolyl phosphate (Roche Molecular Biochemicals, Mannheim, Germany) as substrate. Staining intensity was optimized for double-labeling of LA GABAergic cells. Sections were covered with Crystal Mount and embedded in Permount. An Axioplan microscope with digital image analysis (Metamorph; Visitron, Puchheim, Germany) was used for visualization of these immunohistochemical preparations.

\section{Results}

NMDA receptor-mediated contribution to synaptic transmission in LA interneurons

Data result from recordings in a total of 83 interneurons in the LA that were identified based on intrinsic membrane properties, firing patterns, and morphological features. Neurons were considered for additional analysis if they showed maintained action potential firing with little or no spike frequency adaptation during $+0.1-+0.4 \mathrm{nA}$ current injection from the resting membrane potential (Fig. $1 A a$ ). The resting membrane potential, input resistance as measured from the steady-state voltage response during a $-50 \mathrm{pA}$ current injection from rest, action potential duration at half-maximal amplitude, and steady-state firing frequency at $+0.4 \mathrm{nA}$ current injection were $-69.4 \pm 1.8 \mathrm{mV}$, $291 \pm 13 \mathrm{M} \Omega, 0.7 \pm 0.02 \mathrm{msec}$, and $80.3 \pm 4.2 \mathrm{~Hz}$, respectively $(n=83)$. In addition, the initial component of hyperpolarizing afterpotentials after an action potential displayed a rapid time course of deactivation, thereby imposing a concave trajectory to the overall form of afterhyperpolarizations (data not shown). Time-dependent inward rectification in the hyperpolarizing direction was not pronounced. These properties were similar to those reported previously for interneurons in the LA (Mahanty and Sah, 1998; Szinyei et al., 2000); therefore, we refer to them as such. The intrinsic properties of interneurons were significantly different from those of putative projection cells recorded during the course of the present study $(n=17$; resting input resistance, $186 \pm 12 \mathrm{M} \Omega$; action potential duration at half-maximal amplitude, $1.22 \pm 0.06 \mathrm{msec}$; steady-state firing frequency, $19.3 \pm 1.4$ $\mathrm{Hz})$. Resting membrane potential in projection cells $(-70 \pm 0.9$ $\mathrm{mV}$ ) was not different from that of interneurons. The injection of biocytin and subsequent histological processing revealed that all histologically recovered cells $(n=63)$ that had been classified as interneurons based on electrophysiological criteria possessed dendrites bearing no spines (Fig. $1 A b$ ), thereby corroborating that they represent GABAergic interneurons (McDonald, 1982).

The contribution of NMDA receptor-mediated signals was investigated by stimulating the cortical and thalamic fibers with single shocks at $0.05 \mathrm{~Hz}$ and repetitive shocks at $2 \mathrm{~Hz}$ and applying APV $(50 \mu \mathrm{M})$ after a stable baseline of EPSP subthreshold to spike generation had been obtained. As is evident from the exam-

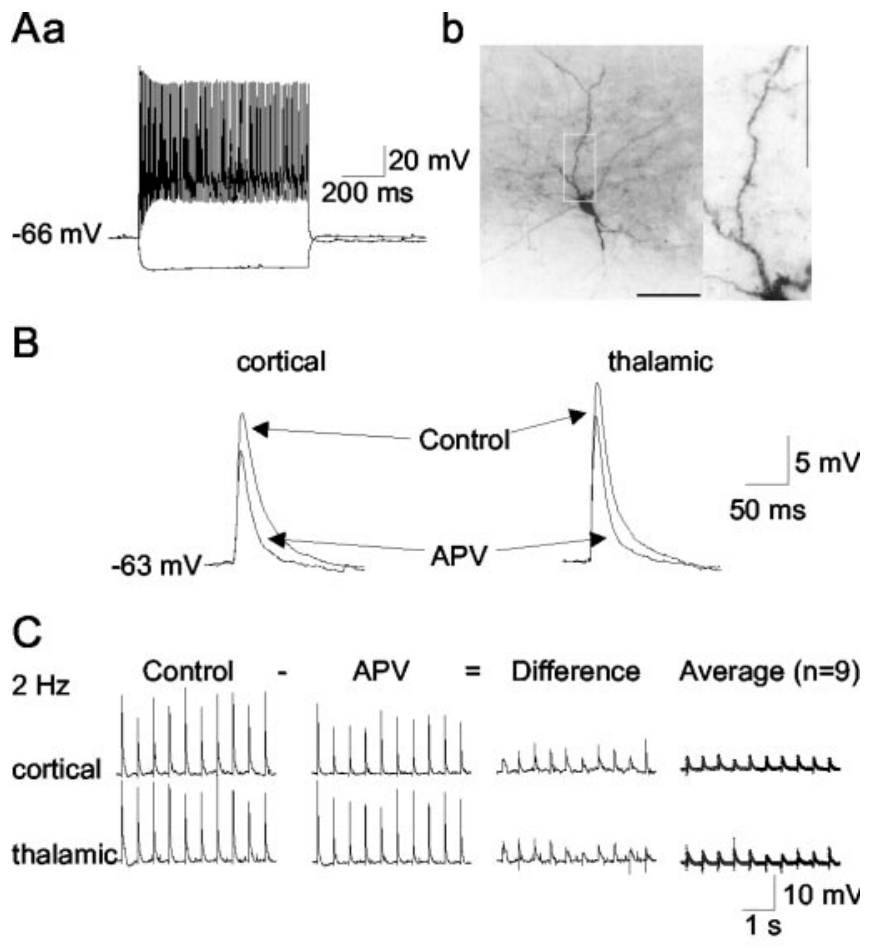

$\mathrm{Da}$

$0.05 \mathrm{~Hz}(\mathrm{~B})$

b

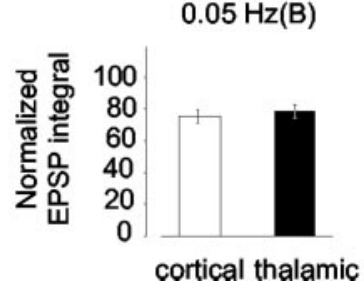

Figure 1. Identification of NMDA receptor-mediated components of EPSPs evoked through stimulation of cortical and thalamic afferent fibers in LA interneurons. A, Electrophysiological $(a)$ and morphological $(b)$ characteristics of a putative interneuron in the LA. Voltage traces $(a)$ represent responses to depolarizing and hyperpolarizing direct current injections $(+0.3,-0.1 \mathrm{nA}$; current traces not shown). Note the tonic series of action potentials with no apparent frequency adaptation. Staining of the same neuron with biocytin $(b)$ reveals nonspiny dendrites; the region within the white frame is shown at a higher magnification. Scale bar, $100 \mu \mathrm{m}$ (corresponding to $25 \mu \mathrm{m}$ in the magnified region). $B$, EPSPs in an interneuron evoked through single shocks $(0.5 \mathrm{~mA}, 100 \mu \mathrm{sec})$ of cortical and thalamic input fibers before (control) and after the application of APV (50 $\mu \mathrm{m})$. C, Responses to repetitive stimulation $(2 \mathrm{~Hz}$ ) of cortical and thalamic pathways, before and after the application of APV $(50 \mu \mathrm{m})$. Difference as calculated from graphical subtraction of the APV signal from the control shows the APV-sensitive component. Average represents the average of subtractions from nine interneurons. D, Average of EPSP integrals after APV treatment with respect to controls at the cortical (open columns) and thalamic (closed columns) pathway for $0.05(a)$ and $2 \mathrm{~Hz}(b)$ afferent stimulation.

ples (Fig. $1 B, C$ ) and averages calculated from integrals of voltage responses to single and repetitive stimulation (Fig. 1D), APV depressed EPSPs at the cortical and thalamic inputs. The amplitude of cortical and thalamic EPSPs was reduced from $17.9 \pm 1.6$ and $21.6 \pm 2.3 \mathrm{mV}$ to $15.5 \pm 1.5$ and $18.5 \pm 2 \mathrm{mV}$ after the application of NMDA receptor antagonist, respectively, corresponding to a reduction to $85.7 \pm 2.1 \%$ and $85.6 \pm 2.2 \%$ of the control value. Calculation of the integrals of EPSPs obtained with single shocks revealed a significant reduction to $75.2 \pm 4.2$ and $78.7 \pm 4.4 \%$ of the control values for cortical and thalamic pathways, respectively (Fig. $1 \mathrm{Da})(n=12)$. The integrals of EPSPs evoked at $2 \mathrm{~Hz}$ were reduced to $69.6 \pm 4.2$ and $79 \pm 4.1 \%$, respectively (Fig. $1 D b)(n=9)$. The effects of APV at thalamic and cortical pathways were similar for stimulation at $0.05 \mathrm{~Hz}$ and 
$-50 \mathrm{mV}, 2 \mathrm{mM} \mathrm{Mg}{ }^{2+}$

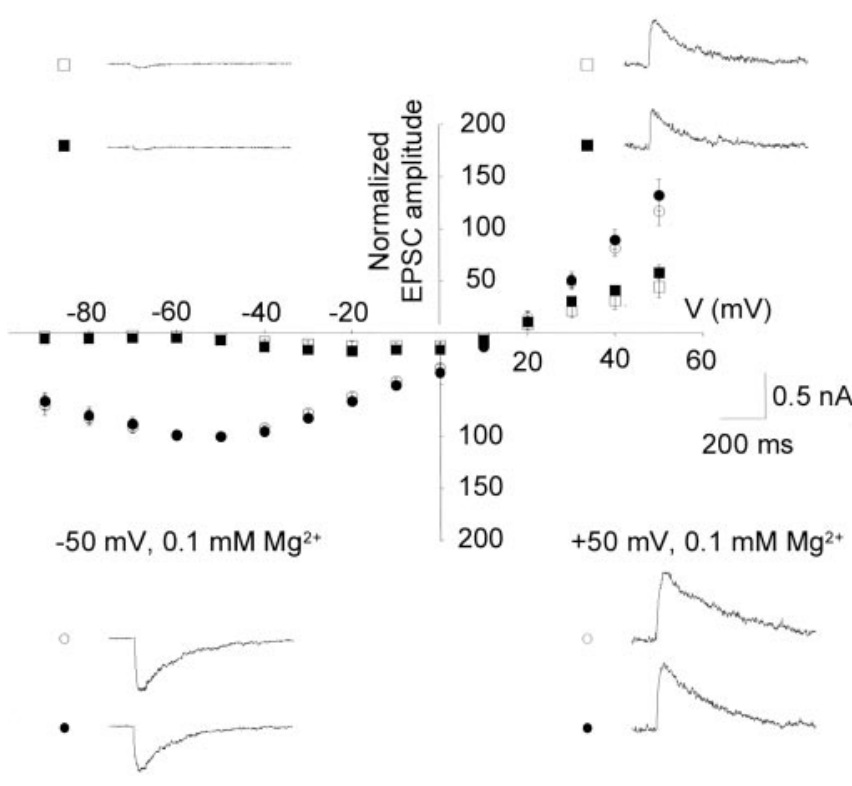

Figure 2. $\mathrm{Mg}^{2+}$-sensitive voltage dependence of pharmacologically isolated NMDA receptor-mediated EPSCs in interneurons. All recordings were obtained during the presence of picrotoxin $(100 \mu \mathrm{M})$, CGP55485 $(10 \mu \mathrm{M})$, and DNQX (10 $\mu \mathrm{M})$. In each interneuron, responses were evoked on stimulation of cortical (open symbols) and thalamic (closed symbols) afferents and were compared in bathing solutions containing 0.1 (circles) and 2 (squares) $\mathrm{mm} \mathrm{Mg}^{2+}$. The holding potential varied in the range -90 to $+50 \mathrm{mV}$. For the construction of $I-V$ relationships, EPSCs were normalized with respect to the EPSC amplitude at $-50 \mathrm{mV}$ in $0.1 \mathrm{~mm} \mathrm{Mg}^{2+}$, and responses were averaged from recordings in 11 interneurons. Traces represent original recordings from one interneuron under experimental conditions as indicated. Stimulus artifacts have been removed for clarity.

reached a small but significant difference $(p=0.016)$ for stimulation at $2 \mathrm{~Hz}$.

Furthermore, the application of DNQX $(10 \mu \mathrm{M})$ substantially reduced but failed to completely block EPSPs evoked from resting membrane potential at both thalamic and cortical inputs. Indeed, increasing the stimulation strength under these conditions resulted in a substantial increase in the amplitude of the DNQX-insensitive response components at both input pathways, which were sensitive to the application of the NMDA receptor antagonist APV $(50 \mu \mathrm{M})(n=6$; data not shown).

These findings indicate that NMDA receptors are functional in LA interneurons, in that they contribute a significant component to excitatory synaptic responses evoked from resting potential through the activity of the two major sensory input systems. The properties of the NMDA receptor-mediated signals were investigated during pharmacological isolation using voltage-clamp techniques in the next experimental step.

\section{Voltage dependence of NMDA receptor-mediated EPSCs}

Under voltage-clamp conditions, afferent stimulation at different membrane potentials ranging from -90 to $+50 \mathrm{mV}$ revealed EPSCs in interneurons. To pharmacologically isolate NMDA receptor-mediated activity, $\mathrm{GABA}_{\mathrm{A}}$ and $\mathrm{GABA}_{\mathrm{B}}$ receptormediated inhibition and AMPA receptor-mediated excitation were blocked with picrotoxin $(100 \mu \mathrm{M})$, CGP55485 (10 $\mu \mathrm{M})$, and DNQX $(10 \mu \mathrm{M})$, respectively, and the concentration of $\mathrm{Mg}^{2+}$ was reduced to $0.1 \mathrm{mM}$. Under these conditions, maximal EPSC amplitudes of $-765 \pm 140$ and $-651 \pm 130 \mathrm{pA}$ were measured at $-50 \mathrm{mV}$ at the cortical and the thalamic input, respectively $(n=$ 11) (Fig. 2). These EPSCs were sensitive to the application of APV in all tested cells ( $n=5$; data not shown) and are therefore considered to be NMDA receptor-mediated synaptic responses. For the construction of $I-V$ curves, EPSC amplitudes obtained at different holding potentials were normalized in individual cells with respect to the amplitude at $-50 \mathrm{mV}$ in $0.1 \mathrm{mM} \mathrm{MgCl}_{2}$. The normalized and averaged $I-V$ curve obtained from measurements in 11 cells displayed a range of negative slope conductance between -90 and $-60 \mathrm{mV}$ and an apparent reversal potential at $12.8 \pm 1.8$ and $12.7 \pm 1.7 \mathrm{mV}$ for cortical and thalamic EPSCs, respectively $(n=11)$. There was no significant difference in the $I-V$ relationship of EPSCs associated with the two inputs (Fig. 2). The application of a bathing solution containing $2 \mathrm{mM} \mathrm{Mg}^{2+}$ led to a voltage-dependent blockade of the EPSCs, with responses being blocked negative to approximately $-50 \mathrm{mV}(n=6)$ (Fig. $2)$. The apparent reversal potential was not affected (12.5 \pm 1.9 and $12.6 \pm 1.9 \mathrm{mV}$ for cortical and thalamic afferents, respectively). Furthermore, $I-V$ curves of EPSCs under these conditions did not reveal differences between cortical and thalamic inputs.

\section{Contribution of NR2B subunits}

To evaluate the possible contribution of NR2B subunits, ifenprodil was used. NR1/NR2B receptor complexes are severalhundred-fold more sensitive to ifenprodil than are NR1/NR2A receptors, and ifenprodil at $10 \mu \mathrm{M}$ has been reported to nearmaximally block the NR2B receptor subtype with no substantial effect on the NR2A subtype (Williams, 1993). In the following experiments, NMDA receptor-mediated responses in LA interneurons were pharmacologically isolated as before. The application of ifenprodil at $10 \mu \mathrm{M}$ reduced the NMDA receptormediated EPSPs in all interneurons that were tested $(n=6)$ (Fig. $3 A a)$. Inhibition reached a steady-state level $\sim 20 \mathrm{~min}$ after application, corresponding to a reduction of EPSPs to $44.8 \pm 5.4$ and $47.9 \pm 5.7 \%$ of the predrug values at the cortical and thalamic inputs, respectively. Significant differences between the cortical and thalamic input systems with respect to the action of ifenprodil in interneurons were not observed. In contrast, ifenprodil $(10 \mu \mathrm{M})$ had no significant effect on DNQX-sensitive AMPA receptor-mediated EPSCs, which were recorded during the continuous presence of APV $(50 \mu \mathrm{M})$ in interneurons held at membrane potentials close to the presumed $\mathrm{Cl}^{-}$equilibrium potential $(-75 \mathrm{mV})$ to minimize the contribution of $\mathrm{GABA}_{\mathrm{A}}$ receptor-mediated synaptic currents $(n=4)$ (Fig. $3 A b)$. The AMPA EPSC amplitudes recorded $15 \mathrm{~min}$ after the application of ifenprodil averaged to $95.7 \pm 4.8$ and $103.7 \pm 5.4 \%$ with respect to control values before drug application for the cortical and thalamic pathways, respectively.

In various types of cells, synapses with a high NR2B content have been observed to contribute a slow component to the synaptic NMDA current, with time constants of decay typically exceeding $200 \mathrm{msec}$ (Chen et al., 1999; Lei and McBain, 2002). Therefore, in a subsequent experimental step, the time course of decay of NMDA currents and the effects of ifenprodil were analyzed in LA interneurons $(n=7)$. The time constant of decay of EPSCs was fitted best by a double-exponential function (Fig. $3 \mathrm{Ba})(r>0.96)$ at both input pathways, with the two time constants averaging $72 \pm 6$ and $60 \pm 5 \mathrm{msec}$ and $423 \pm 63$ and $285 \pm$ $40 \mathrm{msec}$ at cortical and thalamic inputs, respectively $(n=7)$ (Fig. $3 B b)$. The contribution of the fast and the slow components to the total EPSC was $59 \pm 7.5$ and $41 \pm 7.5 \%$ for the cortical input and $61.8 \pm 6.8$ and $38.2 \pm 6.8 \%$ for the thalamic input (Fig. $3 B c$ ). Differences between the two input pathways were not significant. The application of ifenprodil similarly affected the two components of NMDA receptor-mediated EPSCs. With ifenprodil, the 

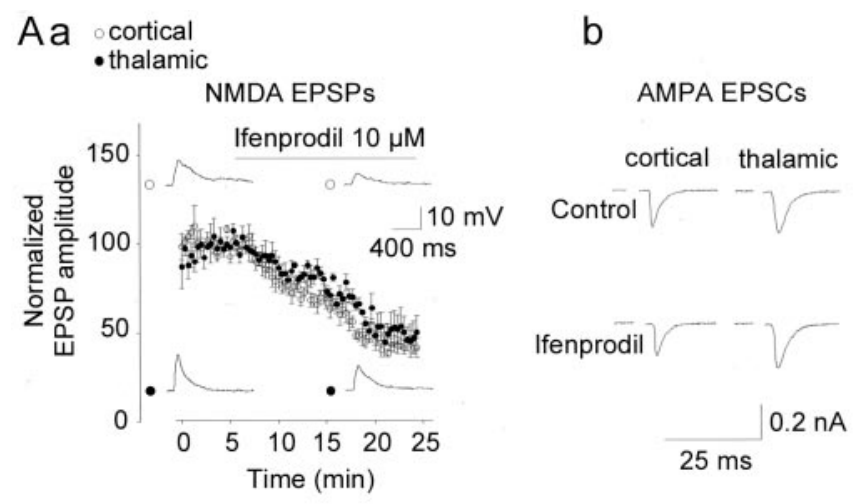

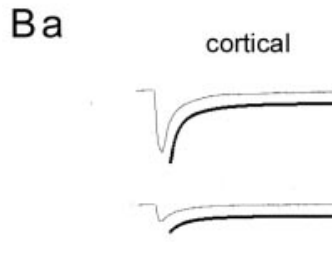

b

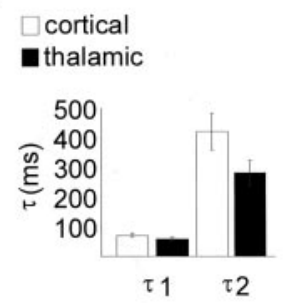

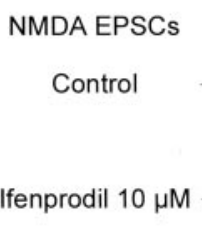

C

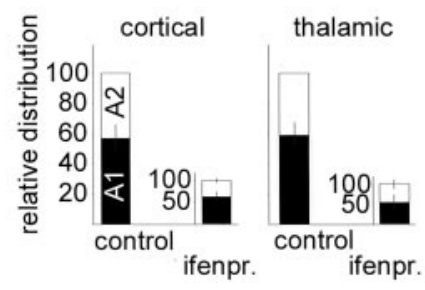

Figure 3. Effects of the NR2B antagonist ifenprodil on NMDA receptor-mediated synaptic responses in interneurons. $A a$, Time course of ifenprodil action on NMDA receptor-mediated EPSPs obtained on stimulation of cortical (open symbols) and thalamic (closed symbols) input fibers $(n=6)$. Responses were obtained at resting potential, during the presence of picrotoxin $(100 \mu \mathrm{M})$, CGP55485 $(10 \mu \mathrm{M})$, and DNQX (10 $\mu \mathrm{M})$. EPSP amplitudes were normalized with respect to baseline values before application, separately for each pathway in each neuron. The bar indicates application of the drug. Traces represent original recordings from one interneuron before and during the maximal action of ifenprodil. Stimulus artifacts were removed for clarity. $b$, Lack of effect of ifenprodil on AMPA receptor-mediated EPSCs. Examples of cortically and thalamically evoked EPSCS in an LA interneuron obtained during the continuous presence of APV $(50 \mu \mathrm{M})$, before and $15 \mathrm{~min}$ after the application of ifenprodil $(10 \mu \mathrm{M})$ are shown. The cell was held at $-75 \mathrm{mV}$. B, Decay kinetics of NMDA receptor-mediated EPSCs. $a$, Time course of decay of NMDA receptor-mediated EPSCs obtained on stimulation of cortical (left column) and thalamic (right column) afferents in an interneuron before (control) and during maximal action of ifenprodil (at $10 \mu \mathrm{M}$ ) is described by a two exponential function (lines below original traces). $b$, Fast and slow time constants $(\tau)$ of EPSC decay, at cortical and thalamic inputs, averaged from recordings in seven interneurons. $c$, Relative contribution of the fast and slow components to EPSCs before (control) and during the maximal action of ifenprodil $(10 \mu \mathrm{M})$. Fast and slow components were calculated as $A 1$ and $A 2$ from the equation in Materials and Methods, and the overall amplitudes of EPSCs during ifenprodil (ifenpr.) were normalized with respect to control values. Recordings were obtained during the presence of picrotoxin (100 $\mu \mathrm{M})$, CGP55485 (10 $\mu \mathrm{M})$, and DNQX (10 $\mu \mathrm{M})$.

NMDA receptor-mediated EPSCs were reduced to $30.1 \pm 3.7$ and $27.2 \pm 3.6 \%$ of the control value at cortical and thalamic inputs, respectively. The relative contribution of the two components to the overall EPSC remained unchanged (fast component, $60.5 \pm$ 6.4 and $53.7 \pm 11.7 \%$; slow component, $39.5 \pm 6.4$ and $46.3 \pm$ $11.7 \%$ at the cortical and the thalamic pathway; $p=0.892$, cortical; $p=0.475$, thalamic) (Fig. $3 B c$ ).

It is noteworthy that significant effects of ifenprodil were also observed on NMDA receptor-mediated EPSPs $(n=3)$ and EPSCs $(n=5)$ in a sample of projection neurons recorded during the course of the present study, thereby corroborating and ex-
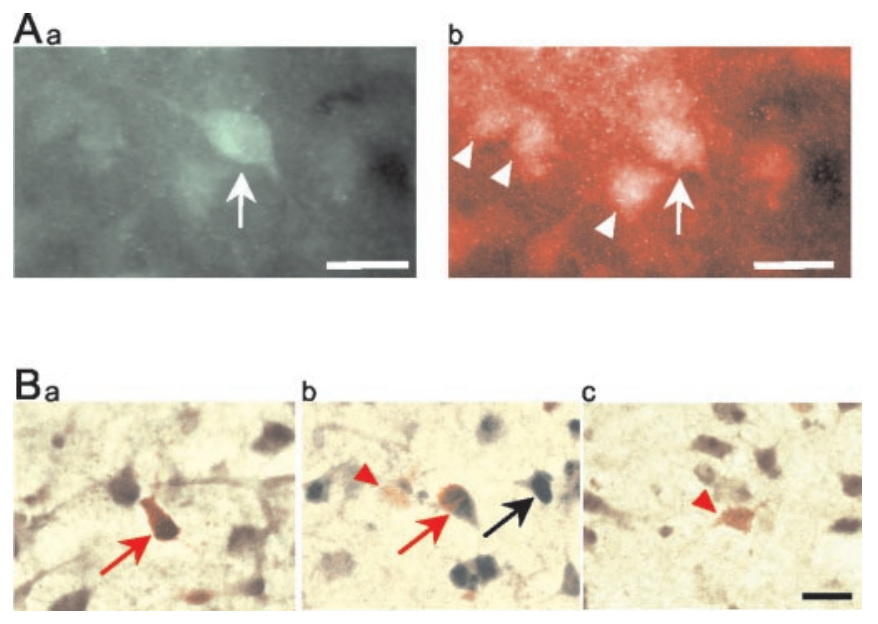

Figure 4. Expression of NR2B subunit in LA neurons, demonstrated through double-labeling immunohistochemistry $(A)$ and combined in situ hybridization/immunohistochemistry $(B)$. $A a$, Green fluorescence in the cell body and proximal dendrites depicts a GABA-immunoreactive interneuron (arrow). Ab, Red fluorescence indicates the localization of NR2B subunits on the same neuron (arrow). Other NR2B-immunoreactive cells are GABA negative and most likely represent projection neurons (arrowheads). $B$, Red staining indicates GABA-immunoreactive neurons in the LA, some of which are colabeled (red arrows in $a$ and $b$ ) for NR2B mRNA (brown reaction product). NR2B mRNA expression is also evident in a number of GABA-negative cells (black arrow in b). Examples of NR2B-negative GABA-immunoreactive cells are indicated by the red arrowheads in $b$ and c. Scale bars, $20 \mu \mathrm{m}$.

tending recent findings on the functional importance of NR2B receptors in this class of LA neurons (Bauer et al., 2002). Interestingly, ifenprodil differentially affected the fast and slow components of NMDA currents in projection neurons $(n=5)$. Under control conditions, the decay time constants of NMDA currents were fitted best by a double-exponential function, with the fast and slow components averaging $70 \pm 7$ and $401 \pm 70 \mathrm{msec}$ (cortical input) and $63 \pm 9$ and $406 \pm 41 \mathrm{msec}$ (thalamic input) and contributing $50.2 \pm 6.3$ and $49.8 \pm 6.3 \%$ (cortical) and $66.8 \pm 1.8$ and $33.2 \pm 1.8 \%$ (thalamic) to the total EPSC. The application of ifenprodil reduced the NMDA EPSCs to $34.5 \pm$ $6.6 \%$ (cortical input) and $45 \pm 2.3 \%$ (thalamic input) of the control value. The effects of ifenprodil were significantly larger on the slow compared with the fast component ( $p=0.011$, cortical; $p=0.035$, thalamic), in that (at cortical and thalamic inputs) the fast component contributed $79.1 \pm 3.5$ and $73.2 \pm 2 \%$, whereas the slow component contributed $20.9 \pm 3.5$ and $26.8 \pm$ $2 \%$ to the residual current.

\section{Expression of NR2B subunits in LA GABA neurons}

The expression of NR2B subunits on GABA-immunoreactive neurons of the LA was demonstrated through doubleimmunohistochemical-labeling and immunohistochemistry/in situ hybridization double-labeling. GABA-immunoreactive neurons were found scattered throughout the slice in cortical and subcortical areas, including the LA (Fig. 4Aa). NR2B subunits were widely expressed in these brain areas, and doubleimmunohistochemical-labeling revealed a colocalization of NR2B subunits with literally all GABA-immunoreactive cells in the LA (Fig. $4 A b$ ), in addition to their expression on a large number of GABA-negative cells (Fig. $4 A b$ ).

To validate these immunohistochemical findings further and to confirm that GABA and NR2B subunits were coexpressed in LA neurons, an immunohistochemical labeling of GABA was combined with in situ hybridization for NR2B. NR2B mRNA was found to be widely expressed in non-GABAergic cells in the 
amygdaloid and neocortical structures of the slice. In addition, a large number of GABA-immunoreactive cell bodies were positive for NR2B mRNA (Fig. 4Ba,b), although GABA-immunoreactive NR2B-negative neurons could also be found (Fig. $4 B C$ ). The size and shape of double-labeled cells were reminiscent of the heterogeneous group of class II neurons, which are thought to represent the majority of GABAergic interneurons in the LA (McDonald, 1985). Strongly GABA-immunoreactive small perikarya that may resemble GABAergic class III neurons (McDonald, 1985 ) could also be found. These were always negative for NR2B, but detection of NR2B mRNA in such neurogliaform cells may well have been prevented by their intense GABA labeling. Occasionally, weakly GABA-immunoreactive pyramid-shaped neurons were found in the LA; however, the majority of pyramidal cells remained GABA negative even after extensive overdevelopment of the staining. In a representative sample of slices $(n=4)$, $78 \%$ of the GABA-immunoreactive neurons (i.e., 193 of a total of 246) were also positive for NR2B, as revealed through doubleimmunohistochemical-labeling or immunohistochemistry combined with in situ hybridization. The actual proportion of double-labeled cells may be even higher, because in some cells the immunohistochemical reaction product may have been covered after the development of in situ hybridization.

\section{Discussion}

The present study was undertaken to elucidate further the functional role of NMDA receptors in synaptic transmission in the LA, with particular emphasis on interneurons and NR2B subunits. The data of the present study indicate the following: (1) NMDA receptor-mediated responses contribute to basal synaptic transmission in putative interneurons of the rat LA. (2) NMDA receptor-mediated currents in interneurons display $\mathrm{Mg}^{2+}$ dependent voltage dependence. (3) NMDA currents evoked on stimulation of cortical and thalamic inputs to interneurons were not significantly different. (4) Both GABA-immunopositive and GABA-immunonegative neurons in the rat LA express the NR2B receptor protein. (5) NR2B subunits contribute to NMDA receptor-mediated responses associated with thalamic and cortical input fibers in both interneurons and projection neurons.

\section{NMDA receptor-mediated synaptic responses at cortical and thalamic inputs in interneurons}

There is some evidence suggesting that NMDA receptormediated excitatory responses exist in interneurons of different brain regions, but these findings are controversial. For instance in the rat neocortex, interneurons apparently lack NMDA receptormediated responses (Ling and Benardo, 1995), although evidence for the existence of NMDA receptors has also been provided (Thomson, 1997). Entorhinal cortical (Jones and Buhl, 1993), thalamic (Pape and McCormick, 1995; Williams et al., 1996), and hippocampal interneurons (Sah et al., 1990; Morin et al., 1996; Lei and McBain, 2002), however, were shown to possess functional NMDA receptors, although some hippocampal interneuronal populations seem to lack NMDA receptor-mediated signals (Sah et al., 1990). In interneurons of the rat lateral and basolateral amygdala, the stimulation of cortical afferents has been reported to lead to AMPA receptor-mediated responses, with only a minimal or negligible contribution from NMDA receptors (Mahanty and Sah, 1998). However, the results of the present study demonstrate that activation of NMDA receptors significantly contributes to the glutamatergic response obtained at resting potential in
LA interneurons. This contribution of NMDA receptors was observed after the stimulation of cortical and thalamic input fibers, and most likely reflects a direct effect of thalamic and cortical fibers acting on postsynaptic NMDA receptors in the interneurons under study: (1) $\mathrm{Mg}^{2+}$-sensitive voltage dependence of postsynaptic currents typical of NMDA-mediated currents was apparent when the membrane potential of the recorded interneurons was changed. This could not be expected if the mediating NMDA receptors were located at presynaptic sites. (2) Application of APV had no consistent effect on the amplitude of the postsynaptic response at hyperpolarized levels of the membrane potential. (3) Pharmacologically isolated NMDA currents typically displayed a smoothly rising phase and constant latency, and the kinetics was similar to those observed in other central neurons (Lei and McBain, 2002), thereby suggesting that they represent monosynaptic responses. (4) Substantially higher stimulus intensities were needed to evoke EPSPs (and spike firing) in projection cells than in interneurons, making it unlikely that EPSPs obtained at a given stimulus strength in interneurons predominantly represent feedback effects via axon collaterals of projection cells. (5) Evidence for the existence of NR2B receptor subunits on GABA-immunoreactive neurons in the LA was obtained on the mRNA and protein level. In particular, a considerable proportion of GABA-immunoreactive class II neurons in the LA appear to express NR2B.

These results add to our previous findings of functional NMDA receptors in interneurons of the rat LA (Danober et al., 2000) the notion that these receptors contribute to basal synaptic transmission at both the thalamic and the cortical input system. However, it cannot be deduced from available data whether NMDA and AMPA receptor subunits are colocalized at the same synapse in interneurons, as has been found for projection neurons of the basolateral amygdala (Farb et al., 1995; Smith and Dudek, 1996).

Experiments performed in Sprague Dawley rats at postnatal days 21-35 indicated that distinct populations of NMDA receptors contribute to synaptic transmission in LA projection neurons at cortical and thalamic inputs, in that the fractional contribution of NMDA receptors was higher and NMDA responses were more sensitive to $\mathrm{Mg}^{2+}$ at thalamic compared with cortical input synapses (Weisskopf and LeDoux, 1999). A similar study performed in Wistar rats at a slightly younger age (postnatal days 17-25) found no indication for differences of NMDA receptormediated responses at the two major input systems to LA projection neurons (Mahanty and Sah, 1999). In LA interneurons recorded in the present study, NMDA receptors contributed to the evoked synaptic responses at thalamic and cortical inputs. Furthermore, the properties of NMDA currents appeared similar at the two input systems, with respect to $\mathrm{Mg}^{2+}$-sensitive voltage dependence, kinetics, and pharmacological properties (indicating the contribution of NR2B subunits; see below). However, it should be kept in mind that NMDA receptor-mediated events were studied at the level of evoked synaptic responses, and that the possibility cannot be excluded that differences between the two afferent input pathways exist at the level of the unitary and/or quantal events (Gil et al., 1999). In any case, the conclusion is that NMDA receptor-mediated responses do exist in LA interneurons at thalamic and cortical synaptic inputs, which is in line with our previous hypothesis that these two major afferent systems to LA interneurons are rather symmetrically organized in functional terms (Szinyei et al., 2000). 


\section{Role of NR2B receptor subunits}

Native NMDA receptors are formed by the heteromeric expression of the NR1 subunit with one type or a combination of NR2 subunits (for review, see Dingledine et al., 1999). While the NR1 subunit is required for the ion-channel pore, the NR2 subunits are important elements in the determination of the unique properties of the NMDA receptors, including unitary conductance, ligand-binding affinity, and kinetics of gating, desensitization, and deactivation. In particular, NMDA receptor-mediated currents at synapses bearing a high number of NR2B subunits have been shown to possess relatively slow decay kinetics compared with synapse-expression NR2A subunits (Monyer et al., 1994; Flint et al., 1997; Chen et al., 1999). In LA interneurons, the decay of the NMDA receptor-mediated currents was described best by a two exponential function, with the fast and the slow component contributing approximately equally to the overall current. The slow component with a time constant of $>200 \mathrm{msec}$ is indicative of synapses with a high NR2B content, as evidenced from observations in various cell types (Chen et al., 1999; Lei and McBain, 2002). Indeed, ifenprodil at a concentration that is considered selective for the NR2B receptor subtype (Williams, 1993) significantly reduced the evoked NMDA current in LA interneurons. It is noteworthy that in LA interneurons, fast- and slow-decaying components were similarly reduced by ifenprodil, whereas in the sample of projection neurons, the slow component was predominantly affected. This may indicate a difference in the kinetics of NR2B-mediated currents between interneurons and principal cells, similar to the difference reported for AMPA receptormediated EPSCs (Mahanty and Sah, 1998). Interestingly, in developing mouse hippocampal neurons, NMDA components displaying fast versus slow decay kinetics were also found to be equally sensitive to ifenprodil (Kirson and Yaari, 1996).

The existence of NR2B subunits in both types of LA neurons is corroborated by the results of the combined immunohistochemical and in situ hybridization experiments. These clearly demonstrated NR2B expression at the cell surface and NR2B mRNA in the perikarya of GABA-immunoreactive neurons in the LA. GABA immunoreactivity in the LA closely matches the expression pattern of glutamic acid decarboxylase and appears to be specific for class II and class III interneurons (McDonald, 1985). Most double-labeled cells, according to their form and size, in fact appeared to be class II neurons (Fig. $4 B a, b$ ). We also found some weakly GABA-labeled pyramidal-shaped cells (Fig. 4Bb), but it was not possible to decide whether these were class I or class II neurons. However, because overdevelopment of the GABA staining did not produce any additional labeling in the LA, it appears that the low levels of metabolic GABA that may be present in its principle neurons have remained below the detection limit.

In various systems, the subunit composition of NMDA receptors is developmentally regulated in that the NR2B subunits tend to be highly expressed at early postnatal stages and are progressively replaced by NR2A subunits during development (Monyer et al., 1994; Flint et al., 1997; Cathala et al., 2000). However, significant numbers of NMDA receptors with a high level of NR2B composition also seem to exist at mature stages, as deduced from recordings in rat hippocampal interneurons at late postnatal age (later than postnatal day 30) (Lei and McBain, 2002). The findings in the present study (performed at postnatal days 21-18) are in line with those observations and suggest that NMDA receptors with a high content of NR2B subunits play a role at cortical and thalamic synapses in interneurons as well as in projection neurons of the LA.
The slow decay kinetics of the NMDA currents with high NR2B content is considered an important element to promote $\mathrm{Ca}^{2+}$ entry and induction of synaptic plasticity (Chen et al., 1999). The specific functional importance of NR2B subunits in the amygdala is demonstrated by the recent finding that intraamygdala infusion of ifenprodil disrupted the acquisition but not the expression of fear conditioning (Rodrigues et al., 2001). In line with this is the observation that the application of ifenprodil blocked long-term potentiation at thalamic input pathways to projection neurons in vitro (Bauer et al., 2002). Synaptic responses to single afferent stimuli were found to be reduced by APV but not ifenprodil in that study, which seems to be in contrast to the present finding that NR2B receptor subtypes contribute to isolated NMDA responses evoked from a membrane potential close to the resting value. The underlying reasons remain unknown, but may relate to the different types of recorded cells or the experimental conditions in the two studies [recording of mixed EPSPs (Bauer et al., 2002) vs recording of isolated NMDA EPSPs/EPSCs (present study)]. In any case, the results of the present study indicate that synapses to both projection neurons and interneurons are potential substrates for NR2B-mediated influences on plastic changes related to fear conditioning. Moreover, the colocalization of NMDA/NR2B and $\mathrm{Ca}^{2+}$-permeable AMPA receptors (Mahanty and Sah, 1999) at cortical inputs to LA interneurons could provide multiple routes for $\mathrm{Ca}^{2+}$ entry, with an impact on synaptic transmission and plasticity. Overall, our results also support the view that signal processing in amygdaloid synaptic circuits is under the critical control of GABAergic mechanisms (Lang and Paré, 1997, 1998; Danober and Pape, 1998; Szinyei et al., 2000; Stork et al., 2002).

\section{References}

Bauer EP, Schafe GE, LeDoux JE (2002) NMDA receptors and L-type voltage-gated calcium channels contribute to long-term potentiation and different components of fear memory formation in the lateral amygdala. J Neurosci 22:5239-5249.

Callahan PM, Paris JM, Cunningham KA, Shinnick-Gallagher P (1991) Decrease of GABA-immunoreactive neurons in the amygdala after electrical kindling in the rat. Brain Res 555:335-339.

Cathala L, Misra C, Cull-Candy S (2000) Developmental profile of the changing properties of NMDA receptors at cerebellar mossy fiber-granule cell synapses. J Neurosci 20:5899-5905.

Chen N, Luo T, Raymond LA (1999) Subtype-dependence of NMDA receptor channel open probability. J Neurosci 19:6844-6854.

Danober L, Pape HC (1998) Mechanisms and functional significance of a slow inhibitory potential in neurons of the lateral amygdala. Eur J Neurosci 10:853-867.

Danober L, Heinbockel T, Driesang RB, Pape HC (2000) Synaptic mechanism of NMDA-mediated hyperpolarization in lateral amygdaloid projection neurons. NeuroReport 11:2501-2506.

Davis M (2002) Role of NMDA receptors and MAP kinase in the amygdala in extinction of fear: clinical implications for exposure therapy. Eur J Neurosci 16:395-398.

Dingledine R, Borges K, Bowie D, Traynelis SF (1999) The glutamate receptor ion channels. Pharmacol Rev 51:7-61.

Farb CR, Aoki C, LeDoux JE (1995) Differential localization of NMDA and AMPA receptor subunits in the lateral and basal nuclei of the amygdala: a light and electron microscopic study. J Comp Neurol 362:86-108.

Flint AC, Maisch US, Weishaupt JH, Kriegstein AR, Monyer H (1997) NR2A subunit expression shortens NMDA receptor synaptic currents in developing neocortex. J Neurosci 17:2469-2476.

Gil Z, Connors BW, Amitai Y (1999) Efficacy of thalamocortical and intracortical synaptic connections: quanta, innervation, and reliability. Neuron 23:385-397.

Gloor P (1992) Neurobiological aspects of emotion, memory and mental dysfunction. In: The amygdala (Aggleton JP, ed), pp 505-538. New-York: Wiley-Liss. 
Heinbockel T, Pape HC (2000) Input-specific long-term depression in the lateral amygdala evoked by theta frequency stimulation. J Neurosci 20 :RC68(1-5).

Jones RS, Buhl EH (1993) Basket-like interneurones in layer II of the entorhinal cortex exhibit a powerful NMDA-mediated synaptic excitation. Neurosci Lett 149:35-39.

Kirson ED, Yaari Y (1996) Synaptic NMDA receptors in developing mouse hippocampal neurones: functional properties and sensitivity to ifenprodil. J Physiol (Lond) 497:437-455.

Lang EJ, Paré D (1997) Similar inhibitory processes dominate the responses of cat lateral amygdaloid projection neurons to their various afferents. J Neurophysiol 77:341-352.

Lang EJ, Paré D (1998) Synaptic responsiveness of interneurons of the cat lateral amygdaloid nucleus. Neuroscience 83:877-889.

LeDoux JE (2000) Emotion circuits in the brain. Annu Rev Neurosci 23:155-184.

LeDoux JE, Farb CR, Milner TA (1991) Ultrastructure and synaptic associations of auditory thalamo-amygdala projections in the rat. Exp Brain Res 85:577-586.

Lei S, McBain CJ (2002) Distinct NMDA receptors provide differential modes of transmission at mossy fiber-interneuron synapses. Neuron 33:921-933.

Levine J, Chengappa KN, Gershon S, Drevets W (2001) Differentiating primary pathophysiologic from secondary adaptational processes. Depress Anxiety 14:105-111.

Li XF, Stutzmann GE, LeDoux JE (1996) Convergent but temporally separated inputs to lateral amygdala neurons from the auditory thalamus and auditory cortex use different postsynaptic receptors: in vivo intracellular and extracellular recordings in fear conditioning pathways. Learn Mem 3:229-242.

Ling DS, Benardo LS (1995) Recruitment of $\mathrm{GABA}_{\mathrm{A}}$ inhibition in rat neocortex is limited and not NMDA dependent. J Neurophysiol 74:2329-2335.

Mahanty NK, Sah P (1998) Calcium-permeable AMPA receptors mediate long-term potentiation in interneurons in the amygdala. Nature 394:683-687.

Mahanty NK, Sah P (1999) Excitatory synaptic inputs to pyramidal neurons of the lateral amygdala. Eur J Neurosci 11:1217-1222.

McDonald AJ (1982) Neurons of the lateral and basolateral amygdaloid nuclei: a Golgi study in the rat. J Comp Neurol 212:293-312.

McDonald AJ (1985) Immunohistochemical identification of $\gamma$-aminobutyric acid-containing neurons in the rat basolateral amygdala. Neurosci Lett 53:203-207.

McDonald AJ (1998) Cortical pathways to the mammalian amygdala. Prog Neurobiol 55:257-332.

Monyer H, Burnashev N, Laurie DJ, Sakmann B, Seeburg PH (1994) Developmental and regional expression in the rat brain and functional properties of four NMDA receptors. Neuron 12:529-540.

Morin F, Beaulieu C, Lacaille JC (1996) Membrane properties and synaptic currents evoked in CA1 interneuron subtypes in rat hippocampal slices. J Neurophysiol 76:1-16.

Neher E (1992) Correction for liquid junction potentials in patch clamp experiments. Methods Enzymol 207:123-131.
Pape HC, McCormick DA (1995) Electrophysiological and pharmacological properties of interneurons in the cat dorsal geniculate nucleus. Neuroscience 68:1105-1125.

Pesold C, Treit D (1995) The central and basolateral amygdala differentially mediate the anxiolytic effects of benzodiazepines. Brain Res 671:213-221.

Rainnie DG, Asprodini EK, Shinnick-Gallagher P (1991) Excitatory transmission in the basolateral amygdala. J Neurophysiol 66:986-998.

Rainnie DG, Asprodini EK, Shinnick-Gallagher P (1993) Intracellular recordings from morphologically identified neurons of the basolateral amygdala. J Neurophysiol 69:1350-1362.

Rodrigues SM, Schafe GE, LeDoux JE (2001) Intra-amygdala blockade of the NR2B subunit of the NMDA receptor disrupts the acquisition but not the expression of fear conditioning. J Neurosci 21:6889-6896.

Romanski LM, LeDoux JE (1993) Information cascade from primary auditory cortex to the amygdala: corticocortical and corticoamygdaloid projections of temporal cortex in the rat. Cereb Cortex 3:515-532.

Sah P, Hestrin S, Nicoll RA (1990) Properties of excitatory postsynaptic currents recorded in vitro from rat hippocampal interneurones. J Physiol (Lond) 430:605-616.

Sanders SK (1995) Regulation of anxiety by $\mathrm{GABA}_{\mathrm{A}}$ receptors in the rat amygdala. Pharmacol Biochem Behav 52:701-706.

Smith BN, Dudek FE (1996) Amino acid-mediated regulation of spontaneous synaptic activity patterns in the rat basolateral amygdala. J Neurophysiol 76:1958-1967.

Stork O, Stork S, Pape HC, Obata K (2001) Identification of genes expressed in the amygdala during the formation of fear memory. Learn Mem 8:209-219.

Stork O, Ji FY, Obata K (2002) Reduction of extracellular GABA in the mouse amygdala during and following confrontation with a conditioned fear stimulus. Neurosci Lett 327:138-142.

Szinyei C, Heinbockel T, Montagne J, Pape HC (2000) Putative cortical and thalamic inputs elicit convergent excitation in a population of GABAergic interneurons of the lateral amygdala. J Neurosci 20:8909-8915.

Thomson AM (1997) Activity-dependent properties of synaptic transmission at two classes of connections made by rat neocortical pyramidal axons in vitro. J Physiol (Lond) 502:131-147.

Turner BH, Herkenham M (1991) Thalamoamygdaloid projections in the rat: a test of amygdala's role in sensory processing. J Comp Neurol 313:295-325.

Washburn MS, Moises HC (1992a) Electrophysiological and morphological properties of rat basolateral amygdaloid neurons in vitro. J Neurosci 12:4066-4079.

Washburn MS, Moises HC (1992b) Inhibitory responses of rat basolateral amygdaloid neurons recorded in vitro. Neuroscience 50:811-830.

Weisskopf MG, LeDoux JE (1999) Distinct populations of NMDA receptors at subcortical and cortical inputs to principal cells of the lateral amygdala. J Neurophysiol 81:930-934.

Williams K (1993) Ifenprodil discriminates subtypes of the N-methyl-Daspartate receptor: selectivity and mechanisms at recombinant heteromeric receptors. Mol Pharmacol 44:851-859.

Williams SR, Turner JP, Anderson CM, Crunelli V (1996) Electrophysiological and morphological properties of interneurones in the rat dorsal lateral geniculate nucleus in vitro. J Physiol (Lond) 490:129-147. 